\title{
A Self-Consistent Model of Melting, Magma Migration and Buoyancy-Driven Circulation Beneath Mid-Ocean Ridges
}

\author{
DAVID R. SCOTT \\ Seismological Laboratory, California Institute of Technology, Pasadena
}

DAVID J. STEVENSON

Division of Geological and Planetary Sciences, California Institute of Technology, Pasadena

\begin{abstract}
Numerical modeling and analysis are used to investigate the processes leading to the eruption of mantle-derived magma at mid-ocean ridges. Our model includes the following effects: melting due to decompression, magma migration by percolation, and circulation of the mantle driven by both the oceanic plates and the distribution of buoyancy beneath the ridge. The distribution of buoyancy is due to both the low density of the liquid and the difference in the density of the residual solids relative to unmelted mantle material. The calculation of densities is based on a simple petrological model in which garnet-spinel lherzolite melts to form a basaltic liquid and a harzburgite residue. We find that the system spontaneously evolves to a state in which a rapid upwelling beneath the ridge axis, faster than the plate velocity, is confined laterally by stably stratified residual material beneath the newly formed plates. This effect is exaggerated if a modest decrease in the shear viscosity of the solid upon melting is included. Our results provide a simple explanation for the narrowness of the zone of crustal formation at mid-ocean ridges. The model also predicts a transition from steady state to episodic crustal formation as the spreading velocity is reduced, perhaps giving rise to along-axis variations in the character of seafloor spreading. The narrow, rapid upwelling gives rise to substantial porosities at depths that are a large fraction of the depth to the solidus. This may allow the liquid at depth to segregate into macroscopic channels, which would account for the consensus from experimental petrology that the liquids parental to MORB are derived from well below the base of the crust.
\end{abstract}

\section{INTRODUCTION}

\subsection{Mid-Ocean Ridges}

The spreading of the oceanic plates and the formation of new oceanic crust at mid-ocean ridges are essential features of plate tectonics [Vine, 1966] A range of observations have improved our understanding of the structures and processes at these plate boundaries. The list of examples we reference here is not comprehensive but includes studies to which our model may be particularly applicable.

Submarine mapping and sampling have provided increasingly detailed observations of surficial structures and processes at mid-ocean ridges. The neovolcanic zone at all ridges, regardless of spreading rate, is at most a few kilometers wide. All ridges show morphological variations along strike, but these variations are more pronounced in slower spreading ridges the axial high of the fast spreading East Pacific Rise [MacDonald et al., 1984] is continuous over many tens of kilometers, whereas the morphology of the slow spreading Mid-Atlantic Ridge varies rapidly along strike The variations in the latter case have been interpreted in terms of along-axis changes from constructiondomınated spreading to stretchıng-domınated spreading [Karson et al., 1987].

${ }^{1}$ Now at Department of Earth Sciences, University of Oxford Parks Road, Oxford OX1 3PR, United Kingdom.

Copyright 1989 by the American Geophysical Union.

Paper number $88 \mathrm{JB03740.}$

0148-0227/89/88JB-3740\$05.00
Seismic exploration has provided improved constraints on the structures at depth, revealing that the seismically defined crust forms very close to the ridge axis [Detrick et al., 1987, McClain et al., 1985] and does not thicken significantly with age [McClain and Atallah, 1986].

Observations of ophiolites provide further information about the likely structure of the oceanic crust and lithosphere. In particular, the pattern of flow in the asthenosphere beneath a mid-ocean ridge may be preserved in foliations observed in ophiolites [Rabinowicz et al., 1987]. Experimental studies of the petrology of mid-ocean ridge basalts (MORBs) provide constraints on, among other things, the depth at which the liquids parental to MORBs segregate from coexisting mineral phases [Stolper, 1980]. The conclusion is that the parental liquids are not in equilibrium with a harzburgite residue until the pressure is increased to well above the pressure at the base of the oceanic crust, implying that the parental liquids are delivered to the crust from considerable depth with little modification.

A number of interpretations of these and other types of data pertaining to mid-ocean ridges have been proposed. Klein and Langmuir [1987] have correlated the chemistry of MORBs with the physical characteristics of axial depth and crustal thickness, which in turn probably reflect the temperature of the underlying mantle. Bottinga and Steinmetz [1979] have incorporated a range of geophysical, geochem!cal, and petrological data into a semiquantitative model, but one in which the pattern of flow in the mantle is prescribed. Hall et al. [1986] have deduced the density structure of the crust and mantle close to the ridge from the topography and the gravity field. 
There remains some debate as to the nature of the seismically defined oceanic crust The interpretation upon which we have based our model is that the crust represents igneous rocks that have solidified from mantle-derived liquids at or near the mid-ocean ridge Alternatively, the base of the crust may represent a hydration boundary, with rocks above having experienced alteration due to hydrothermal circulation near the ridge, and rocks below remaining unaltered [Lewis, 1983].

The concept of melt segregation by a percolation mechanism, which is a central feature of the model presented here, was initially discussed by Sleep [1974], and developed by Turcotte and Ahern [1978]. The work presented in this paper arises from more recent advances in the fluid dynamics of magma generation and magma migration by percolation [McKenzie, 1984; Scott and Stevenson, 1986]. A central idea behind these advances has been that the liquid phase in partially molten ultramafic rocks is interconnected even when the amount of liquid present is small [Cooper and Kohlstedt, 1986; Vaughan et al., 1982]. As a result, the buoyancy of the liquid should cause it to migrate upward relative to the solid with ease When considering the processes of melting, magma migration, and crustal formation at mid-ocean ridges [Ribe, 1985; McKenzie, 1985a, b], the general conclusion is that the porosity in a partially molten upwelling beneath the ridge will remain small because the liquid is extracted very efficiently However, simple percolation models fall to explain some of the basic observations of mid-ocean ridges described above. In particular, the models do not account for the narrowness of the zone of crustal formation or the depth from which primary melts are delıvered

Our approach to understanding and relating the observations of mid-ocean ridges, and to assessing models of the formation of oceanic crust, is to construct a quantitative, selfconsistent fluid dynamical model of the unobserved processes taking place in the mantle beneath mid-ocean rldges. By modeling these processes, we can also hope to increase our understanding of the structure and dynamics of the underlying mantle

\section{Motivation for the Model}

We now focus on the observation that the formation of crust at mid-ocean ridges occurs in a narrow zone, which presents a genuine geodynamical problem Consider the simple model illustrated in Figure 1 We know that the oceanic plates spread apart at velocity $V_{s} \sim$ several $\mathrm{cm} \mathrm{yr}^{-1}$. A thickness $z_{c} \sim 6 \mathrm{~km}$ of crust is formed close to the divergent plate boundary ("crust" hereafter refers to the combination of extrusive, intrusive, and cumulate layers, all of magmatic origin). The crust is thought to represent incomplete melting of the parental mantle, the degree of melting $F_{\text {tot }}$ lying in the range of $10-30 \%$. This melting must be due to adiabatic decompression of the mantle as it is drawn up by the spreading plates, crossing its solidus at depth $z_{s o l}$ The velocity and scale width of this upwelling, $V_{u}$ and $x_{u}$, cannot be observed directly

The variables introduced above can be related by balancing the amount of crust produced in unit time to the rate of production of magma in the upwelling. In unit time, a volume $V_{s} z_{c}$ of crust is produced per unit length along the strike of the ridge The rate of melting in the upwelling is

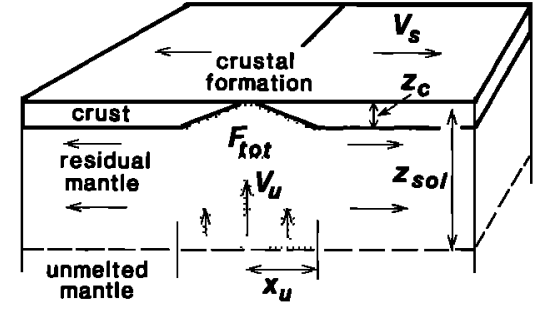

Fig. 1. Schematic of upwelling, melting, and crustal formation beneath a mid-ocean ridge. The dashed line is the solidus of unmelted mantle material. The stippled region is partially molten. Magma escapes from this region to form the crust.

$V_{z} F_{\text {tot }} / z_{\text {sol }}$, and the volume of mantle that is melting at this rate is $Z_{\text {sol }} x_{x}$ per unit length along strike Multiplying these, the amount of liquid produced in unit time is

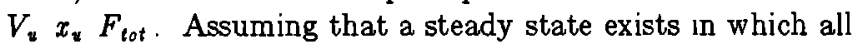
the liquid is extracted to form crust, we obtain the following equality:

$$
z_{c}=\frac{V_{u}}{V_{s}} F_{\text {tot }} x_{u}
$$

Note that the depth of the solidus does not appear directly; we might expect this length scale to appear in such an expression. In reality, both $F_{\text {tot }}$ and $x_{w}$ are expected to depend on $z_{s o l}$. As we assert above, $z_{c}, V_{s}$, and $F_{\text {tot }}$ are reasonably well constrained, whereas $V_{v}$ and $x_{v}$ are not For $V_{s}=3 \mathrm{~cm} \mathrm{yr}^{-1}$ and $F_{\text {tot }}=0.2$, the product $V_{\mathrm{u}} x_{\mathrm{u}}=03 \mathrm{~cm}^{2} \mathrm{~s}^{-1}$

Broad, slow upwelling Let us assume initially that $V_{\mathrm{u}} / V_{\mathrm{s}} \sim 1$. This is the case for virtually any pattern of flow driven only by the plates, e.g, the classic "corner flow" due to diverging plates overlyıng a semi-infinite medium of constant viscosity [Batchelor, 1967] Equation (1) then Implies that $x_{v}>z_{c}$, since $F_{\text {tot }}<<1$. This effect is exaggerated if the extraction of magma from the upwelling is not completely efficient. The problem with a slow, broad upwelling is that the magma must somehow be focussed into the ridge axis, otherwise we would expect to see a broad zone of Igneous activity (of width $\sim x_{u}$ ) on elther side of the ridge

A possible mechanism has been proposed by Speigelman and McKenzie [1987] Normally the percolation of hquid through a partial melt is driven only by the pressure gradient due to the buoyancy of the liquid, which acts only upward. They propose that the nonhydrostatic pressure gradient assoclated with corner flow acts over a wide region to focus the liquid into the ridge While their argument is correct in principle and qualitatıvely appealıng, quantıtatıve considerations show that it calls for an unacceptably high viscosity in the partially molten solid This can be seen by the following rough calculation. The pressure gradient due to shear beneath the ridge is $\sim \eta V_{s} / r^{2}$, where $\eta$ is the viscosity and $r$ is the radial distance from the ridge The pressure gradient due to the buoyancy of the liquid is $\sim g \Delta \rho$, where $\mathrm{g}$ is gravity and $\Delta \rho$ is the density difference between the solid and liquid, approximately $05 \mathrm{~g} \mathrm{~cm}^{-3}$. If the two are to be comparable in the region above the solidus $\left(r \leq 50 \mathrm{~km}\right.$ ), then $\eta \geq 10^{21} \mathrm{~Pa} \mathrm{~s}$ is required. This has also been noted by Phipps Morgan [1987] The mantle directly beneath oceanic plates probably has a viscosity of at most $10^{10} \mathrm{~Pa}$ s [Craig and McKenzie, 1986; Hager and Clayton, 
1988], a value that is expected to drop by as much as an order of magnitude in the region of continuous partial melting beneath the ridge, due to liquid-enhanced creep [Cooper and Kohlstedt, 1984].

The possibility that focussing is caused by anisotropic permeability has also been considered. Phipps Morgan [1987] suggests that the finite strain of mantle material in the upwelling beneath a ridge creates an anisotropic fabric that focusses melt into the ridge axis D J Stevenson and D R. Scott (unpublıshed manuscript, 1987), takıng an alternate view, suggest that the distribution of liquid in a partrally molten rock may be controlled by deviatoric stresses In this case, defocussing of liquid appears to occur beneath the ridge axis. Not enough is known about the physical properties of partial melts to invite confidence in these models

Narrow, rapid upwelling Since the initial assumption leads to difficulties, let us assume instead that the narrow zone of igneous activity at the ridge reflects an equally narrow upwelling. Consıder an upwelling with a width simılar to the thickness of the crust, i.e., $x_{x} \sim z_{c}$ Equation (1) then implies that $V_{\mathrm{u}} \gg V_{s}, 1$ e., the upwelling must be rapid relative to the spreading velocity.

Since the spreading of the plates alone is unlikely to lead to such a pattern of flow, even allowing for a reduction in viscosity beneath the ridge, we conclude that there must be some additional force driving circulation in the mantle beneath ridges The most obvious choice for such a driving force is the buoyancy of the magma in the partially molten upwelling, as studied by Rabinowicz et al. [1987]. A second source of buoyancy is the density difference between the solid residue of partial melting and the parent rock.

In Appendix B, we show that the velocity of an upwelling with viscosity $\eta^{*}$ and a density that is lower than the surroundings by an amount $\Delta \rho$ is approximated by

$$
V_{u} \sim \frac{01 x_{u}^{2} g \Delta \rho}{\eta^{u}}
$$

With $x_{*} \sim 30 \mathrm{~km}$ and $\eta^{4} \sim 10^{18} \mathrm{~Pa} \mathrm{~s}$, we require $\Delta \rho \sim 0003 \mathrm{~g} \mathrm{~cm}^{-3}$ to give $V_{*} \sim 10 \mathrm{~cm} \mathrm{yr}^{-1}$ If the density of the liquid is $0.5 \mathrm{~g} \mathrm{~cm}^{-3}$ less than that of the solid, a porosity of $\sim 1.5 \%$ would give the necessary buoyancy to the whole rock. An alternative test of this idea is to see whether we can satisfy the constraint $V_{u} x_{v}=03 \mathrm{~cm}^{2} \mathrm{~s}^{-1}$ derived earlier We obtain the following expression:

$$
\left(\frac{\Delta \rho}{0.003 \mathrm{~g} \mathrm{~cm}^{-3}}\right)\left(\frac{x_{\mathrm{v}}}{10 \mathrm{~km}}\right)^{3}\left(\frac{10^{18} \mathrm{~Pa} \mathrm{~s}}{\eta^{u}}\right) \sim 1
$$

These crude calculations invite closer investigation.

In this paper we conduct such an investigation, and conclude that it is quite possible for a steady state upwelling of the type described above to exist beneath mid-ocean ridges. In section 2 we define the model more precisely. section 3 describes a series of numerical experiments on the model system, the results of which are analyzed in section 4 and the appendices Section 5 contains our discussion and conclusions

\section{MODEL}

The model we present is based on the following succession of events

1. Surface oceanıc plates spread apart, driven by forces that are not discussed further. The mantle beneath the spreading center is drawn up by the motion of the plates

2. The rising mantle material decompresses adiabatically and, when it reaches its solidus, begins to melt. Melting continues as the material continues to rise The buoyancy of both the liquid and the residual solid relative to unmelted mantle modifies the plate-driven circulation.

3 The partially molten region, above the level at which the rising material first crosses its solidus, is permeable to the movement of the buoyant liquid relative to the crystalline matrix Liquid that migrates in this way, and reaches the surface, segregates from the matrix to form the oceanic crust. As long as the surface plates continue to spread, a steady state can persist in which the melting beneath the ridge supplies the magma that forms the oceanic crust

As usual, the assumptions to be made in setting up a quantitative model of this relatively complex system can be roughly divided into two categories (1) assessing which physical processes are and are not important, and providing a corresponding set of governing equations, and (2) specifying the response of the system to these processes through material properties These assumptions are described in the following sections and are reexamined in section 5 in light of the results obtained in sections 3 and 4

\subsection{Processes and Governing Equations}

Mantle circulation Calculation of the velocity field in the mantle is central to the model. The velocity field $\mathbf{V}$ is approximated by the solution of the Stokes equation for the flow of an incompressible viscous fluid

$$
\nabla \times(\eta \nabla \times \mathrm{V})+\nabla p=g \Delta \rho^{\psi r-m} \hat{\mathbf{z}}
$$

where $\eta$ is the viscosity of the mantle, $p$ is a reduced pressure $\left(p=p_{\text {total }}-g \rho^{m} z\right), g$ is the acceleration due to gravity, $\Delta \rho^{w r-m}$ is the whole rock (solid + liquid) density relative to unmelted mantle, and $\hat{\mathbf{z}}$ is the unit vector in the direction of gravity Note that the viscosity $\eta$ may be spatially varying

We calculate the velocity field in a finite box with one corner at the ridge axis. The velocity field is twodimensional and symmetric about a vertical plane extending down from the ridge It is driven by a constant velocity boundary condition at the free surface and buoyancy forces due to variations in density within the mantle. At the boundaries of the box that are distant from the ridge axis (the bottom and the outer side), we constrain the velocity field to be equal to the analytic solution for plate-driven flow. In effect, we assume that the effect of buoyancy forces is negligible in the mantle distant from the ridge axis.

The velocity field $V$ is divergence-free, i.e, it describes the flow of an incompressible fluid Since the solid must compact to allow the liquid to escape (see below), $V$ is an approximation to the solid velocity field Strictly, $\mathbf{V}$ is the divergence-free "circulation" discussed by Scott [1988]. $\mathrm{V}=\mathbf{v}^{s o l}+f\left(\mathbf{v}^{l i q}-\mathbf{v}^{s o l}\right)$ In an exact treatment, $\mathrm{V}$ would have some dependence on the bulk viscosity of the deformable solid matrix We also adopt the Boussinesq approxımation, i e, the volume change associated with changes in density is neglected

Temperature structure and melting. We simplify the thermodynamics of the melting phase change and heat transport in the system a great deal. First, we assume that the 

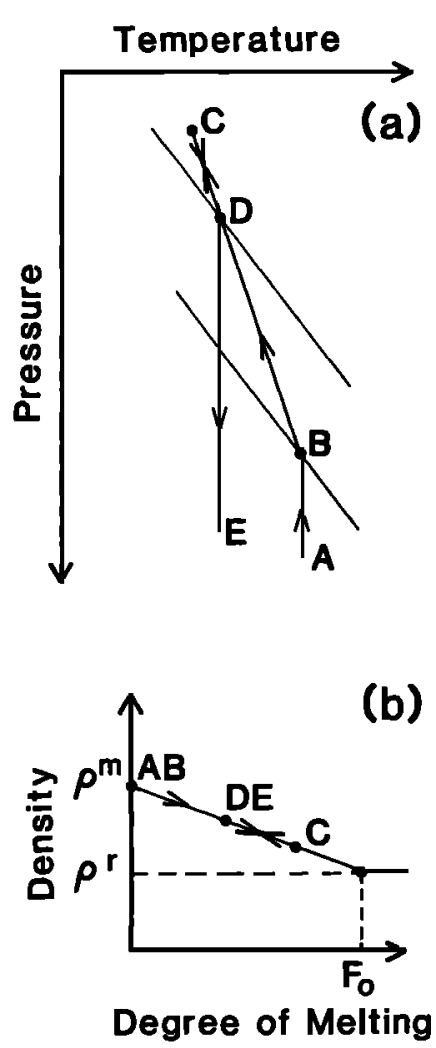

Fig. 2. Melting behavior and density of model mantle material. (a) Typical trajectory in P-T space of the simplified material we use to model the mantle. Melting of the material due to decompression is the only thermodynamic process included. (b) Variation of density of the solid on this trajectory. Unmelted mantle has density $\rho^{m}$; the solid residue after melting a fraction $F_{0}$ of the material has density $\rho^{\gamma}$. The whole rock density also depends on the amount of liquid present. Unmelted material at point $A$ ascends isothermally and reaches its solidus at point $B$. Further ascent to point $C$ is accompanied by melting and cooling due to the removal of latent heat. The intrinsic density of the solid decreases as heavy components are preferentially melted. The majority of the liquid formed escapes upward. The remaining liquid freezes when the material descends from point $C$ to point $D$, increasing the density of the solid slightly. Further descent of the solid residue to point $\mathrm{E}$ is isothermal. Note that the solidus of the material at point $\mathrm{E}$ is at a lower pressure than the original material at point $A$. There are two reasons for this difference: first, the temperature at point $E$ is lowe and, second, the material at point $E$ is intrinsically more refractory If the melting point of material were univariant and points $B, C$ and $D$ lay along a single solidus, the second reason would not apply.

temperature and composition of the upwelling mantle before it melts are laterally uniform. All such material crosses its solidus at the same depth. Implicit here is the assumption that the subsolidus upwelling beneath ridges is "passive," $i$ e., not driven by body forces such as thermal buoyancy [Houseman, 1983]. This differs from an "active" model such as that of Turcotte and Oxburgh [1967], in which the ridge overlies the upgoing limb of a convection cell In their model, the melting starts at greater depth directly below the ridge than to either side.

We believe that, below the cold thermal boundary layer defining the lithosphere and above the solidus, the most important thermodynamic process is the transfer of energy released by decompression to the latent heat of melting. A typical pressure-temperature path associated with this process is illustrated in Figure $2 a$. Assuming that there is no heat transport by conduction, the temperature depends only on the degree of melting of the rock, i.e., on the amount of latent heat that has been extracted. Therefore we do not calculate the temperature structure; implicitly the temperature lies on a wet adiabat when the rock is partially molten, and on a dry adiabat (assumed to be an isotherm) otherwise. We discuss the melting of mantle materials further below.

In the numerical models we neglect thermal conduction and other forms of heat transport. Thermal conduction is of course important close to the surface For example, in solving (4), we have placed the velocity boundary condition at the surface, independent of the horizontal distance from the ridge, implicitly ignoring the thickening of the rigid surface plate by cooling. We assume that this approximation has little effect on the distributions of melting and flow beneath the ridge.

Magma migration. Despite the interest that we and others have shown in the compaction of partial melts, we do not believe that compaction and the bulk viscosity of the matrix are important in controlling magma migration beneath ridges This is because the melting is distributed on a much longer length scale (10-100 km) than likely values of the compaction length or the wavelength of magmons (0 1-1 km). Here we neglect all the nonhydrostatic contributions to the pressure gradient driving flow of the liquid relative to the solid These include contributions due to compaction, and also contributions due to the pattern of shear in the flow field of the rock as a whole. The effect of these latter pressure gradients is discussed in detail by Speigelman and McKenzie [1987].

The resulting form of Darcy's law describes percolation of the liquid through the solid driven only by the vertical pressure gradient due to buoyancy

$$
u_{z}=f\left(v_{z}^{h q}-v_{z}^{s o l}\right)=\frac{k(f)}{\eta^{h q}} g \Delta \rho^{s-l}
$$

In (5), $u_{z}$ is the flux of liquid relative to the solid, $v_{z}^{\text {hq }}$ and $v_{z}^{\text {sol }}$ are the velocities of each phase, $f$ is the porosity, $\eta^{\text {liq }}$ is the viscosity of the liquid, and $\Delta \rho^{s-1}=\rho^{s o l}-\rho^{\text {lig }}$ is the density difference driving flow; $k(f)$ is the permeability, a function of the porosity $f$

Note that we now have two independent flow fields Equation (4) describes an incompressible flow field that, to a very good approximation, is equal to the velocity of the solid matrix. Darcy's law (5) describes the relative motion of the two phases. The velocity of the liquid is therefore made up of the sum of the (approximate) solid velocity from (4), and the relative velocity from Darcy's law (5).

The magnitude of the flux $u_{z}$ at the upper surface is equated to the rate of formation of oceanic crust. The details of the formation of the extrusive, intrusive, and cumulate layers are not addressed by this model. In the way that we have stated this model, the formation of crust should strictly be accompanied by subsidence of the upper boundary of the partially molten region away from the upper surface We neglect this small correction in the solution of (4)

\subsection{Material Properties}

Petrological model and densities. We have adopted a simplified petrological model that emphasizes changes in density during solid state phase changes and the melting 
phase change In setting up this model, we distinguish between ultramafic rocks that have undergone different amounts of melting or that are in equilibrium at different pressures. The differences between these rocks are represented in the numerical experiments primarily by therr densities or, more correctly, their densities relative to one another.

The starting material is unmelted garnet lherzolite (olivine+orthopyroxene+clınopyroxene+garnet, in the approximate proportions $60.20: 10 \cdot 10$ ), intended to represent the bulk of the upper mantle

Rock of this composition undergoes two solid-state phase changes in the depth range 0-150 km [Wood and Yuen, 1983]. At approximately $16 \mathrm{kbar}$, the garnet lherzolite transforms to spinel lherzolite (ol+opx+cpx+sp), which in turn transforms to plagioclase lherzolite $(o l+o p x+c p x+p l)$ at approximately $8 \mathrm{kbar}$ Both these phase changes are accompanied by decreases in density of approximately $1 \%$, somewhat less in the high pressure transformation, somewhat more in the low pressure transformation. We have performed the numerical experiments like those described in section 3 including the effect of these phase transitions However, we find that the results do not differ significantly from a simplified case where the solıd-state phase transitions are lgnored.

In the simplified case, we use an average garnet-spınel lherzolite density $\rho^{m}=3.34 \mathrm{~g} \mathrm{~cm}^{-8}$ for the unmelted mantle. This value is taken from Klein and Langmuir [1987], although it is consistent with values stated in other studies [Oxburgh and Parmentier, 1977, Bottinga and Steinmetz, 1979]

This density corresponds to unmelted material The $\mathrm{gt}+\mathrm{cpx}$ are preferentially melted, leaving a harzburgite or dunite residue (ol \pm opx) after approximately $30 \%$ melting. We use the value $\rho^{7}=3.295 \mathrm{~g} \mathrm{~cm}^{-3}$ for the density of the residue, taken again from Klein and Langmuir [1987] The density of solids that have experienced between $0 \%$ and $30 \%$ melting is obtained by linear interpolation between the unmelted and residual densities (see Figure 2b). Melting more than $30 \%$ (which does not arise in the calculations presented here) would not change the resıdual density further

The density of the liquid produced is assumed to be approximately $2.8 \mathrm{~g} \mathrm{~cm}^{-3}$, a value chosen to represent the average density of a basaltic liquid over the pressure range 0-20 kbar [Rigden et al., 1984]. The important quantity for the purposes of calculation is $\Delta \rho^{s-l}$, the density difference between the liquid and the coexisting solid. Since the solid density is always around $33 \mathrm{~g} \mathrm{~cm}^{-3}$, we assume that $\Delta \rho^{s-1}=0.5 \mathrm{~g} \mathrm{~cm}^{-3}$ for all solid and liquid compositions, at all pressures.

The density of the whole rock (solid and liquid) relative to unmelted garnet-spinel lherzolite depends on the amount that the solid has melted and the amount of liquid remaining. If the volume fraction of liquid is $f$ (equivalent to the porosity), and the degree of melting of the solid is $F$, then the whole rock density is given by

$$
\rho^{w r}(f, F)=\rho^{m}-f \Delta \rho^{s-l}-\frac{F}{F_{0}} \Delta \rho^{m-r}
$$

where $\Delta \rho^{m-r}=\rho^{m}-\rho^{r}$, and $F_{0}$ is the degree of melting at which the density of the solid is reduced to $\rho^{7}$, assumed to be $30 \%$. Equation (6) applies when $F<F_{0}=30 \%$
Rememberıng that melting increases both $f$ and $F$, note that the density always decreases when either $f$ or $F$ increases. Inserting the values for the densities given above, we obtain the following expression for $\Delta \rho^{w r-m}$, the density of the whole rock relative to unmelted mantle, in units of $\mathrm{g} \mathrm{cm}^{-3}$.

$$
\Delta \rho^{\nu r-m}(f, F)=-0.5 f-0.15 F
$$

Other quantities In the numerical results below, all velocities are scaled to the quantity $u_{0}=k_{0} g \Delta \rho^{s-1} / \eta^{l i q}$, where $k=k_{0} f^{2}$ The velocity scale is obtained by nondlmensionalizing Darcy's law We have already adopted a density difference $\Delta \rho^{s-l}=05 \mathrm{~g} \mathrm{~cm}^{-3}$. The viscosity $\eta^{l / q}$ is approximately $10 \mathrm{Pas}$ [Kushiro, 1986], and $k_{0} \sim 10^{-10} \mathrm{~m}^{2}$ for a grain size of $1 \mathrm{~mm}$ [Scott and Stevenson, 1986; Maalpe and Scheie, 1982] With considerable uncertainty, the velocity scale is then $150 \mathrm{~cm} \mathrm{yr}^{-1}$ We investigate the consequences of varyıng this scale in the numerical experiments.

All the remaining parameters are kept fixed The viscosity of the unmelted mantle material is assumed to be $10^{19} \mathrm{Pas}$ The rate of melting due to adiabatic decompression is assumed to be $1 \% \mathrm{kbar}^{-1}\left(0.33 \% \mathrm{~km}^{-1}\right)$ The dense component that forms $30 \%$ of the unmelted garnet lherzolite would therefore be melted completely after $90 \mathrm{~km}(30$ $\mathrm{kbar}$ ) of ascent However, we place the solidus of unmelted garnet lherzolite at $60 \mathrm{~km}(20 \mathrm{kbar})$. This generates the correct crustal thickness [McKenzie, 1984] (see section 3.1)

\subsection{Time Dependence and Steady State}

Since oceanic plates are of much greater horizontal extent than the depth to the solidus, it reasonable to seek a steady state solution for the model that we are developing In steady state, the following balance exists to prevent the porosity from changing

$$
\frac{\partial f}{\partial t}=0=-\frac{\partial u_{s}}{\partial z}-\mathrm{V} . \nabla f+\mathrm{R} V_{z}
$$

The first term on the right-hand side is the rate of compaction of the matrix due to gradients in the flux $u_{z}$. Although we are neglecting the effect of compaction on the pressure gradient in Darcy's law (5), it must nonetheless occur The second term on the right-hand side is the advection of porosity by the circulation $\mathrm{V}$. The third term is the rate of melting, where $\mathrm{R}=F_{\text {tot }} / z_{\text {sol }}$ is the rate of melting due to decompression or ascent. This term is only included if the material is above its solidus; Figure $2 a$ shows how the depth to the solidus changes if the material has already experienced some melting. Implicit in (8) is our adoption of a Boussinesq approximation, i e., while appealing to the buoyancy of the liquid to drive its ascent, we neglect the associated change in volume upon melting

The composition of the solid, parameterized by the degree of melting $F$, is also a variable, and a similar balance is sought:

$$
\frac{\partial F}{\partial t}=0=-\mathrm{V} \cdot \nabla F+\mathrm{R} V_{z}
$$

Again the right-hand side includes an advection term and a melting term, the latter equal to the melting term in (8) Note that we do not include a compaction term for the solid; this is consistent with our omission of the effect of the subsidence of the upper boundary in the solution of the Stokes equation (4). 


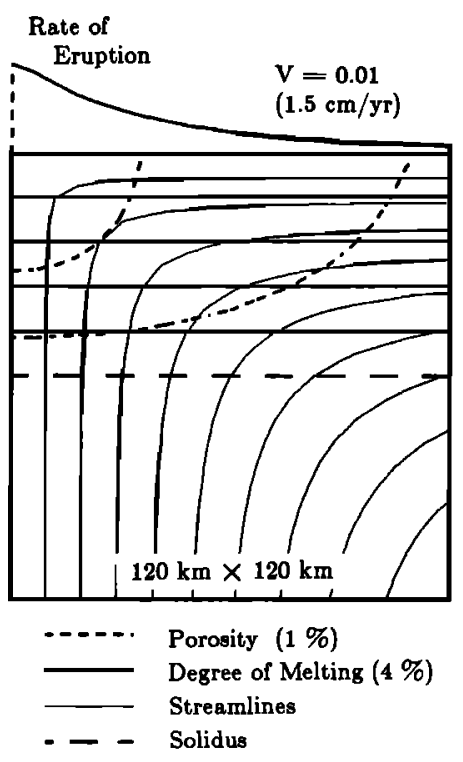

Fig. 3. Steady state flow and distribution of liquid and solid, without buoyancy-driven circulation. The contours of porosity are at intervals of $1 \%$. The contours of the degree of melting are at intervals of $4 \%$.

\section{NUMERICAL EXPERIMENTS}

The numerical method is a simplified version of that used for calculations that include the dynamic effects of compaction, performed by Scott [1988]. The boundary conditions used in the solution of the Stokes equation (4) are described In section 2.1. Note in particular that we impose the analytic solution for flow driven by the plates alone in the mantle distant from the ridge This outer boundary condition is applied along a box twice as large as the frames shown in Figures 3-6

In the numerical examples shown in Figures 3-5, we have found the steady state distribution of liquid as follows.

1. An initial distribution of porosity $f$ and solid composition $F$ is specified. The distribution of buoyancy is calculated using (7).

2. The Stokes equation (4) is solved for $\mathbf{V}$ using a finite element technique.

3. Darcy's law (5) is used to calculate the flux $u_{z}$.
4. The distributions of porosity and solid composition are changed slightly using the time derivatives calculated from (8) and (9). A finite difference scheme is used for these calculations.

5. The sequence is repeated until the time derivative of porosity is negligible everywhere

We used the same technique to trace the time-dependent behavior shown in Figure 6 . The time-stepping scheme used in step 4 is explicit and uses streamline-upwind artificial diffusion to stabilise the advective terms in (8) and (9) We have performed a number of tests on this scheme to ensure that it is stable and sufficiently accurate to lend confidence in the models we present These tests included the advection of simple shapes by varıous velocity fields, and varying the amount of artificial diffusion and the time step used in the experiments presented here

\subsection{Plate-Driven Flow}

The simple case where no buoyancy forces are included provides an introduction to the cases that follow. With only the plates driving flow the pattern of circulation is simple "corner flow," which can be obtained analytically. This case also illustrates the problem discussed in section 1 , wherein a broad, slow upwelling gives rise to a broad zone of crustal formation.

Figure 3 shows the distribution of liquid, the degree of melting, and the pattern of circulation for this case. The figure shows the solution for a particular choice of nondmensional spreading velocity, shown above the frame.

$$
V=\frac{V_{s}}{u_{0}}=0.01=>V_{s} \sim 1.5 \mathrm{~cm} \mathrm{yr}^{-1}
$$

The porosity is higher under the ridge because the ascent velocity and the rate of melting are higher. However, the degree of melting depends only on the distance above the solidus because the circulation is monotonically upward at all distances from the ridge. Also shown in Figure 3 is the rate of eruption at the surface, scaled to its maximum value at the ridge. The rate of eruption is equated to the flux of liquid relative to solid at the surface, given by Darcy's law (5).

Increasing the spreading velocity, which is the only free
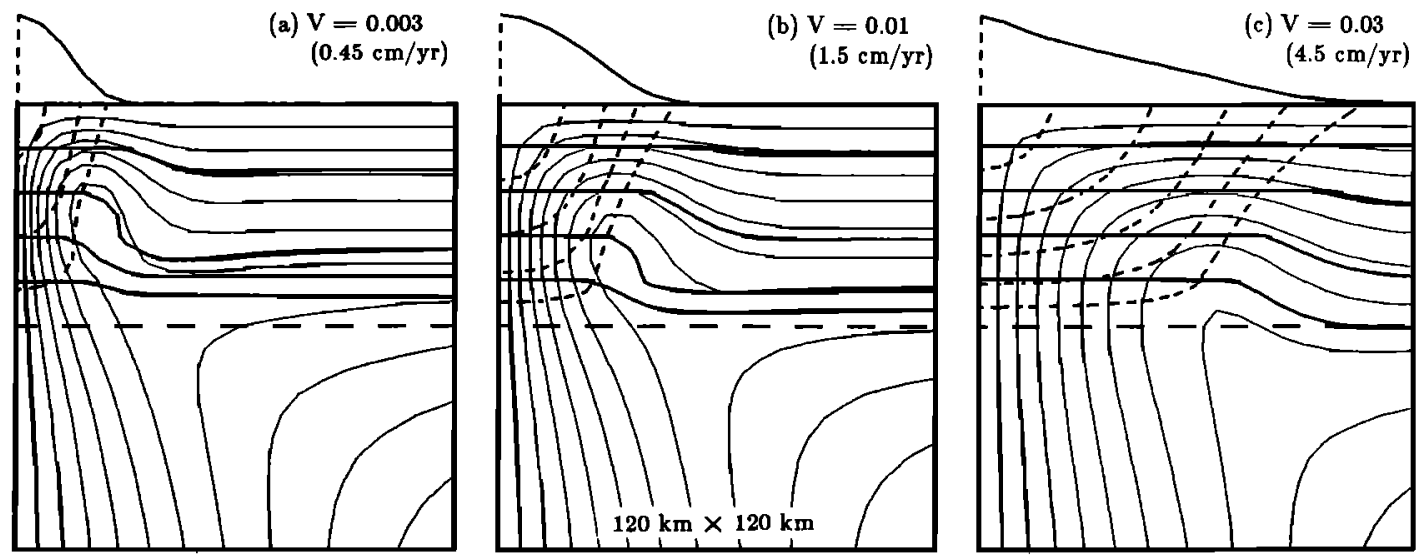

Fig. 4. Steady state flow and distribution of liquid and solid, with buoyancy-driven circulation. Figures $4 a, 4 b$, and $4 c$ show the variation with spreading velocity. The contour interval used for the stream function is proportional to the spreading velocity. 

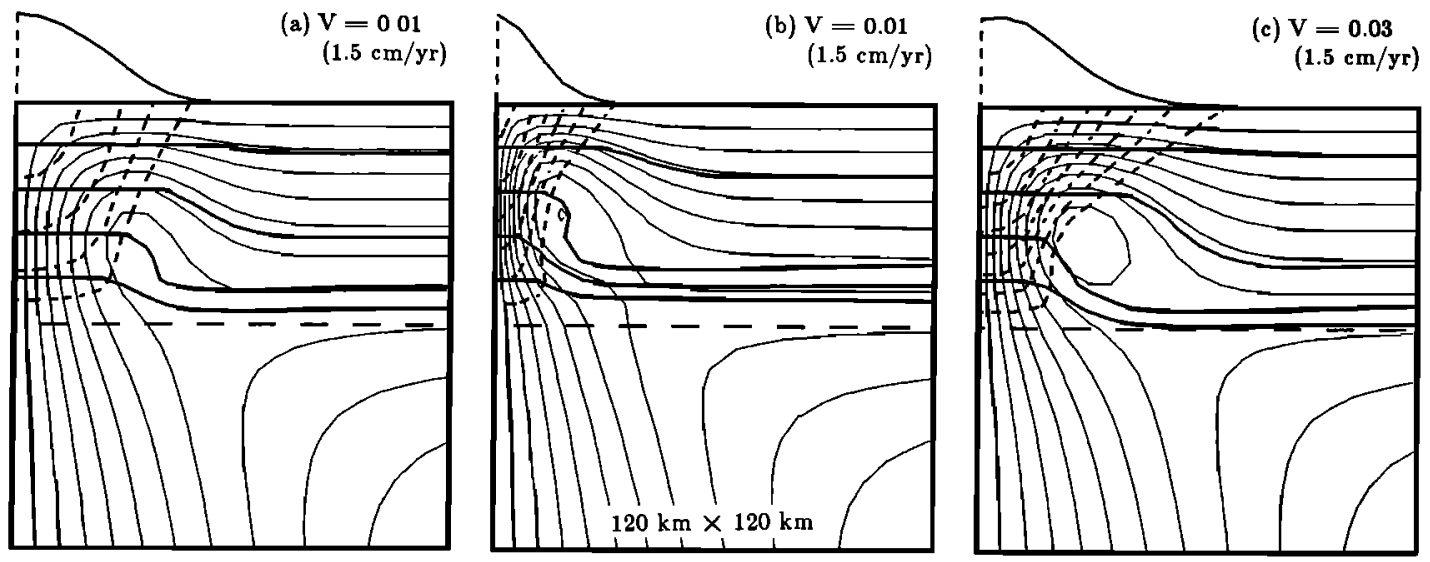

Fig. 5. Steady state flow and distribution of liquid and solid, with buoyancy-driven circulation. Figure $5 a$ is the same as Figure $4 \mathrm{~b}$. In Figure $5 b$, the solid viscosity in the partially molten region is one-fifth of the viscosity elsewhere. In Figure $5 c$, the viscosity is uniform, but the reference permeability $k_{0}$ is reduced by a factor of 0.3 from the value used in Figure $5 a$. Figures $5 a, 5 b$, and $5 c$ have the same dimensional spreading velocity.

parameter, has two effects First, because the rate of melting is higher, the porositıes throughout the partially molten region become higher. This increases the permeability and allows the liquid to escape more quickly. Second, liquid is advected away from the Indge axis more rapidly, so the zone of crustal formation is spread away from the axis.

Conversely, decreasing the spreading velocity reduces the porosities and reduces the lateral advection of liquid. However, while the zone of crustal formation can be spread away from the ridge, it can never become more focussed than the underlying distribution of meltıng

Note that changing the nondimensional spreading velocity can be interpreted in two ways. It may represent a change in the spreading velocity $V_{s}$, or a change in dimensional velocity scale $u_{0}$. Since the velocity scale is proportional to the reference permeability $k_{0}$, the above comments for higher and lower spreading velocities also describe the consequences of lower and higher $k_{0}$, respectively.

With Figure 3 in mind, we can show how the observed thickness of the crust and the likely value of $F_{\text {tot }}$ constrain the depth to the solidus. The layer of stratified residual material leaving the frame to the right has an average degree of melting of $F_{\text {tot }} / 2$, and a thickness $z_{\text {sol }}$. The layer is moving sideways at close to the velocity of the crust at the surface. Therefore in steady state the thickness of the crust formed from the extracted liquid must be $z_{c}=z_{s o l} F_{t o t} / 2$ Using the notation of (8), $F_{\text {tot }}=\mathrm{R} z_{s o l}$, where $\mathrm{R}$ is the rate of melting due to ascent. Hence,

$$
z_{c}=\frac{\mathrm{R} z_{\text {sol }}^{2}}{2}
$$

The quadratic dependence in (11) constrains $z_{s o l}$ to be close to $60 \mathrm{~km}$, if $z_{c}=6 \mathrm{~km}$ and $\mathrm{R}=0.33 \% \mathrm{~km}^{-1}$

\subsection{Flow Driven by Plates and Buoyancy}

The distribution of buoyancy for the case shown in Figure 3 , while not used in the calculation, would be laterally nonuniform because of the distribution of porosity This distribution of buoyancy would therefore modify the pattern of plate-driven flow, tending to increase the upwelling velocity beneath the ridge. Note that initially, the distribution of buoyancy due to the degree of melting would be laterally uniform and would not modify the flow.

The increased upwelling velocity close to the ridge must result in a component of downward return flow nearby. Since the scale length of the lateral variations in porosity in Figure 3 is $z_{\text {sol }}$, the downward return flow must be at approximately this distance from the ridge. Viewing the system on a scale much larger than $z_{\text {sol }}$, the pattern of flow must still be that of plate-driven corner flow. Our initial (a) $\mathrm{t}=0.0$

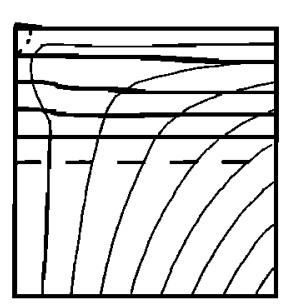

(b) $t=0.1$

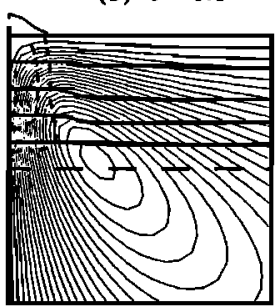

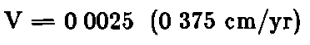
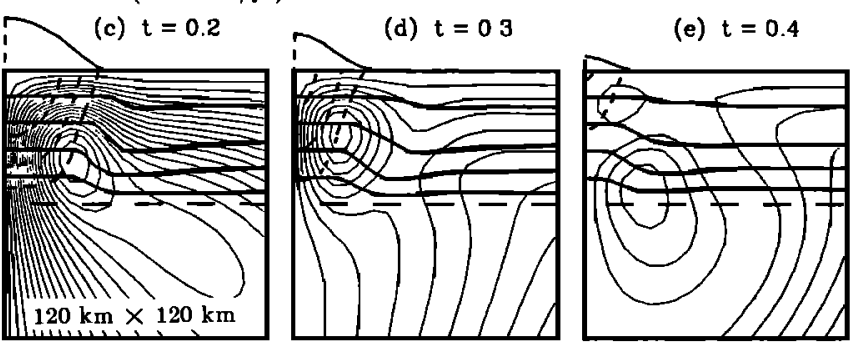

Fig. 6. Time-dependent flow and distribution of liquid and solid, with buoyancy-driven circulation. The spreading rate is slightly smaller than the spreading rate in Figure 4a. The times above each frame are in units of $z_{\text {sol }} / V_{s}$. The episode of unstable upwelling and melting recurs with a period of approximately 0.75 in these units. 
conclusion, like that of Rabinowicz et al. [1984], is that a local pattern of circulation, of scale $z_{s o l}$, is superimposed on the large-scale corner flow.

However, the variation in density of the solid with the degree of melting now becomes important. This is the central idea in this paper The downward return flow will force the residual mantle down toward the denser unmelted mantle Also, the residual material will be juxtaposed with material in the upwelling that has a lower degree of melting, and hence a greater solid density. The residual material will resist the downward motion and reduce the relative buoyancy of the upwelling. The pattern of flow will now be determined by the plate, the distribution of porosity, and the distribution of the degree of melting.

Figure 4 shows the resulting steady state for three values of the scaled spreading velocity. The effect of adding the buoyancy forces is to laterally confine the upwelling above the solidus, particularly at the lower spreading velocities. The confinement is achieved by a step in the buoyancy of the solid, where the residue of melting is forced down by the buoyancy in the upwelling. Note that in Figure 3, the region that is partially molten extends across the entire frame In Figure 4, the downward return flow freezes any liquid that has not escaped. After the liquid has frozen, the contours of the degree of melting parallel the streamlınes

As expected, the effect of adding buoyancy forces becomes less important as the spreading velocity increases. While the zone of crustal formation is convincingly confined in Figures $4 a$ and $4 b$, it is as broad in Figure $4 c$ as it is in Figure 3. Note that the profiles of the rate of eruption above each frame are scaled to a fixed maximum amplitude The area under the profiles does not represent the total amount of crust produced, which is very similar in all three cases. In fact, slightly more crust is produced in Figure $4 a$ because the mean degree of meltıng in the residual mantle is higher

\section{3. The Effects of Reduction in Viscosity and Permeability}

There are good grounds to suppose that the solid-state viscosity of the mantle is reduced when it is partially molten [Cooper and Kohlstedt, 1984] In our model, this will result in a reduced viscosity of the material in the upwelling The upwelling will therefore be faster for a given buoyancy and will generate more downward return flow As shown in Figure 56 , the net effect is to exaggerate the confinement of the upwelling In this case, the viscosity in the partially molten region is reduced by a factor of 5 from the viscosity elsewhere. An accompanying effect is the increase of the porosity in the upwelling

The permeablity is the least well-constrained quantity in this model To illustrate the effect of varying the reference permeability $k_{0}$, Figure $5 c$ shows the effect of a reduction by a factor of 3 This reduces the velocity scale $u_{0}$, so to simulate the same real spreading velocity used in Figures $5 a$ and $5 b$, we have increased the nondimensional spreading velocity. The reduced permeability increases the porosity in the upwelling and exaggerates the narrowing of the lower part of upwelling. However, the liquid escapes slowly from the upper part of the upwelling and is therefore transported laterally by advection.

\subsection{The Breakdown of Steady State at Low Spreading Velocities}

The sequence of cases shown in Figure 4 poses the question of how the system behaves at lower spreading veloci- ties. The suggestion is that even greater confinement of the upwelling than that in Figure $4 a$ might be expected Instead, we find that a steady state cannot be achieved at lower spreading velocities. The experiment shown in Figure 6 is the same as that shown in Figure $4 a$, but with the scaled spreading velocity $V$ reduced from 0003 to 00025 The behavior we find is episodic, with bursts of rapid upwelling and melting interspersed by periods of slow flow with little or no melting In the following section we develop an understanding of this interestıng transition from steady to episodic behavior

\section{ANALYSIS}

The analysis outlined here and detailed in the appendices is guided closely by the numerical experiments described above It is ad hoc in that no consistent analytic solution to the governing equations is obtained, but it has improved our understanding of the balance of buoyancy forces in the system. The most interesting result is that the reason for the transition between steady state and episodic behavior can be qualitatıvely identified.

\subsection{Outline of Analysis}

Consider the geometry shown in Figure 7. In section A.1 we investigate the dependence of the density of the upwelling, and of the "walls" of residual material on either side, on the spreading velocity. This leads to an approximate relationship between the width of upwelling $x_{s}$ and the spreading velocity $V_{s}$ :

$$
(1-x) V-B x^{5 / 2} V^{1 / 2}+A x^{3}(1-x)=0
$$

where $x=x_{u} / z_{s o l}$ and $V=V_{s} / u_{0} \quad A$ and $B$ are positive constants The function, shown in Figure 8 , has the following characteristics.

1 Real solutions for $V$ are obtained only if

$$
x \geq x_{\min }=\frac{2 A^{1 / 2}}{B+2 A^{1 / 2}}
$$

The value of $V$ when $x=x_{\min }$ is

$$
V\left(x_{\min }\right)=\frac{8 A^{5 / 2}}{\left(B+2 A^{1 / 2}\right)^{3}}
$$

2. The global minimum of $V$ is at $V=0, x=1$ Elsewhere $V$ is always positive.

3. The transitional region characterized by the minima in $V$ and $x$ joins two asymptotic branches. For a given value of $V, x$ has a large value $\left(V \sim x^{3}\right)$ and a small value

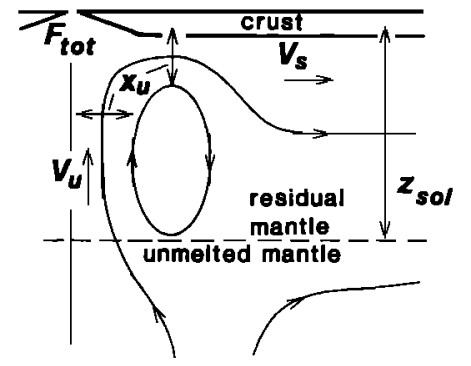

Fig. 7. Pattern of flow beneath a mid-ocean ridge. The analysis in Appendix $A$ is based on this simplified version of the pattern seen in the numerical experiments. 


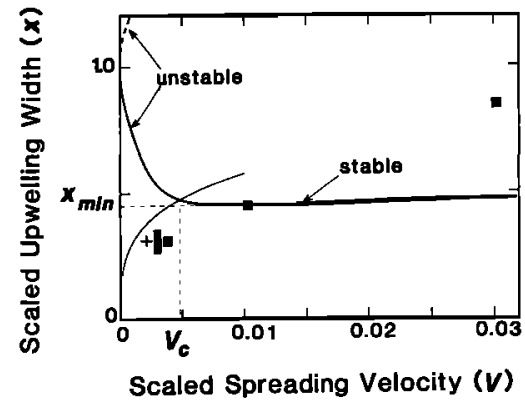

Fig. 8. The relationship between spreading velocity and upwelling width. The heavy solid and dashed lines show $V(x)$ as given by (A11), with $A=0.11$ and $B=0.81$. The dashed branch, in the top left corner, is unstable due to porosity runaway. The light solid line is the stability condition for the oscillation of density mechanism, given by (A26) with $\sigma=0$. The intersection between this line and $V(x)$ is at $V_{c}$. The solid symbols indicate the position of steady state solutions, as estimated from the numerical experiments. The first solid symbol represents the experiment shown in Figure $4 a(V=0.003)$; the symbol is enlarged in the $x$ direction because we observed persistent oscillations of $x$ in this experiment. The cross adjacent to the first solid symbol represents the experiment shown in Figure $6(V=0.0025)$, where a steady state was not found. The experimentally determined value of $V_{c}$ therefore lies in the range $0.0025<V_{c}<0.003$.

$\left(V \sim x^{5} /(1-x)^{2}\right)$. Physically, the former corresponds to a state where the buoyancy of the liquid in the upwelling is dominant. The latter corresponds to a state of balance between the buoyancy of the liquid and the negative buoyancy of the solid relative to the walls.

In section A.2 we analyze the stability of (A11) using two approaches. The first approach suggests that the large $x$ branch is unstable due to "porosity runaway," i.e., unchecked increase in the porosity and buoyancy of the upwelling.

The second approach suggests that the balance between the density of the upwelling and the density of the walls cannot be maintained at low spreading rates, because it takes too long for residual material to be transported from the upwelling to the walls. Specifically, the equilibration time for the density of the walls is $\tau_{v}=z_{\text {sol }} / V_{\mathrm{v}}$

Suppose that the velocity of the upwelling increases; this increases the porosity and decreases the density of the upwelling, which provides positive feedback to the velocity. The positive feedback can be controlled because the more rapid, narrower upwelling produces a residue with a higher degree of melting and lower density. When this material is delivered to the walls the relative buoyancy of the upwelling is reduced, providing negative feedback to the upwelling velocity. However, this negative feedback is delayed by a time $\tau_{\nu}$.

In Figure 8 we indicate a critical spreading velocity $V_{G}$, which is estimated through a mathematical analysis of this delayed feedback. At higher spreading velocities a stable steady state should exist. At lower velocities, "oscillation of densities" in the upwelling and walls prevents the development of a steady state.

\subsection{Comparison with Numerical Experiments}

The values of the various material properties stated in section 2 are reiterated below.

$$
\begin{aligned}
z_{s o l} & =60 \mathrm{~km} \\
k_{0} & =10^{-10} \mathrm{~m}^{2} \\
\eta^{l t q} & =10 \mathrm{Pas} \\
\eta^{*} & =10^{19} \mathrm{Pas} \\
F_{t o t} & =02 \\
F_{0} & =0.3 \\
\Delta \rho^{m-t} & =0.045 \mathrm{~g} \mathrm{~cm}^{-3} \\
\Delta \rho^{s-1} & =0.5 \mathrm{~g} \mathrm{~cm}^{-3}
\end{aligned}
$$

With these values, we obtain the following values for the numerical constants in (A11): $A=0.11$ and $B=081$ The lines plotted in Figure 8 correspond to these values.

The analysis predicts $x_{\mathrm{min}}=045$ In estimating $x$ from the numerical experiments, we use $x=V_{s} / V_{u}$, where $V_{v}$ Is the maximum velocity on the upwelling (see (A2)) This is probably an underestimate, but may be obtained easily and consistently from a series of experiments. This gives $x_{\mathrm{min}}=0.32$, in reasonable agreement with the theoretical prediction.

The observed variation of $x_{\min }$ with $\eta_{*}$ and $k_{0}$ is also consistent with the theory. A decrease in either $\eta_{u}$ or $k_{0}$ should decrease $x$ min. When a lower viscosity is used for the partially molten region of the upwelling, as in Figure $5 b$, a value of $x$ lower than 0.32 is observed. The same applies when $k_{0}$ is reduced. A notable failure of the analysis is in predicting a very slow increase of $x$ with $V$. In the numerical experiments, $x$ increases from 0.32 to 0.86 when $V$ increases by a factor of 10 from $V_{c}$. This may be because the approxımation for the upwelling velocity obtained in Appendix B becomes poor as $V$ and $x$ increase.

We find reasonable agreement in the minimum spreading velocity for steady state solutions. The analysis predicts $V_{c}=0.0048$. We find $0.003>V_{c}>0.0025$. These bounding cases are lllustrated in Figures $4 a$ and 6 .

Referring to the experiment illustrated in Figure $4 a$, we have found that the steady state is approached very slowly. Weak oscillations in $x$ persist for many cycles, with a period of approximately $0.5 z_{s o l} / V_{s}$. The theoretical prediction of the period of oscillation of densities close to $V=V_{c}$ is $2 \tau_{w} \sim 06 z_{s o l} / V_{s}$. This agreement lends us some confidence in our choice of the mode of instablity

\section{Discussion}

\section{1. Assessment of the Model}

In order to assess the robustness and relevance of the model, we reexamine the assumptions described in section 2

Mantle circulation The viscosity structure that we have used in solvıng the Stokes equation (4) is probably simpler than that found beneath a real mid-ocean ridge. In Figure $5 b$, we show how a reduction in viscosity in the upwelling, due to the presence of liquid, causes additional narrowing of the upwelling. We have not modeled the effects of a temperature or stress-dependent viscosity. However, since the upwelling is generally hotter (see Figure $2 a$ ) and moving more quickly than the walls, both effects will probably lower the viscosity in the upwelling and exaggerate the narrowness of the upwelling.

The box used for the experiments is twice as large as the frames shown in the figures (see Appendix B). At the bottom and outer side of the box, we prescribe as boundary 
conditions the analytic solution for flow driven by the plate only. This appears to be a satisfactory assumption, since most of the experiments show the effect of buoyancy to be confined to a region close to the ridge axis It is possible that these boundary conditions are influencing the progress of the experiments shown in Figures $4 c$ and 6

We have assumed that the flow field in (4) is divergence free, Ignoring the volume change due to melting and the compaction of the solid matrix as liquid escapes. Also, we ignore the movement of the upper boundary associated with these changes in the interior Implementing an exact treatment of these effects is possible but would complicate the numerical method The volume changes due to melting and compaction are dispersed over a large depth interval and probably have no significant dynamic effect. The subsidence of the upper boundary, which accumulates to about $10 \%$ of $z_{s o l}$ when all the crust is formed, may have some dynamic effect when the upwelling is very narrow, as in Figure $5 b$.

The model is two-dimensional, and we have not investlgated the stability of our steady state solutions in three dimensions It is quite possible that steady or episodic solutions exist in three dimensions

Temperature structure and melting. The dynamic and thermodynamic consequences of the thickening of the oceanic lithosphere due to cooling by thermal conduction are not included in our calculations The frame shown in the figures is approxımately $120 \mathrm{~km}$ wide; for a spreading velocity of $1 \mathrm{~cm} \mathrm{yr}^{-1}$, the lithosphere would be about $30 \mathrm{~km}$ thick beneath the crust leaving the frame. This thickness is half the depth to the solidus indicated by the dashed lines in the figures Inspecting the figures with this in mind suggests that this region of cooling by conduction will not affect the melting in the upwelling, although it may affect the transport of residual material to the walls

Magma migration. The microscopic appearance and material properties of the partially molten region beneath a ridge remain poorly known This ignorance is our principal source of reservation about the resemblance of our model system to real mid-ocean ridges Experımental observations of partially molten ultramafic rocks are a cornerstone of this work, but have been confined to conditions of hydrostatic stress. In these conditions, the experiments suggest that the permeability should have a simple dependence on the porosity (such as the form $k \sim f^{2}$ that we have used), because the topology of the liquid phase is simple Theoretical work (D. J. Stevenson and D. R. Scott, unpublished manuscript, 1987) suggests that, in the presence of deviatoric stresses, the topology of the liquid phase will be more complex. As a result, the permeability may be substantially reduced and may be anisotropıc. Another possibility is that a rock containing several percent liquid and subjected to shear may develop liquid-filled fractures [Nicolas and Jackson, 1982]. Such fractures would radically alter both the permeability and the effective shear viscosity of the rock. We comment on the petrological implications of such a process below.

In defense of the relevance of our model, we assert that the rate of escape of liquid from the partially molten material in the upwelling will probably be limited by percolation on the scale of the grain size, simply because melting occurs pervasively throughout the rock.

Petrological model and densities. An important input to our model is the assertion that the density of the solid residue of partial melting is lower than the unmelted mantle.
This difference results in the lateral confinement of the upwelling. If the parental material were a plagıoclase lherzolite, rather than a garnet or spinel lherzolite, the harzburgite residue would be more, instead of less, dense. In the Earth, the phase transition to plagioclase lherzolite on a mantle adiabat occurs at about $8 \mathrm{kbar}(25 \mathrm{~km})$, well above the depth to the solidus that we have assumed. We have performed experiments which include the changes in the density structure due to this effect, and find that it makes very little difference The effect of the changes is small because of the proximity of the material affected to the upper boundary; since there is no vertical flow through the boundary, density anomalies close to the boundary drive very little flow

We speculate that in a planet where the solid densities have a different relationship, a radically different pattern of igneous activity would be expected

\subsection{Observational Implications}

We present our fluid dynamical model as a candidate solution to the problem posed in section 12 , i.e, why the zone of crustal formation at mid-ocean ridges is narrow. However, other features of the model have implications for the interpretation of observations of mid-ocean ridges, and in this section we widen our view from fluld dynamics to discuss these implications.

Episodicity in seafloor spreading. The submarine mapping and sampling performed by Karson et al. [1987] along the slow spreading Mid-Atlantic Ridge reveals substantial variations in the mechanism of seafloor spreading at different points along the axis In certain regions there is abundant volcanic actıvity, suggestıng crustal extension by construction, i e, the addition of new mantle-derived igneous rocks. In other regions, no more than a few tens of kilometers away, there is no volcanic activity and the suggestion that crustal extension is accommodated by stretching. Furthermore, recent observations of the nearby Kane fracture zone suggest that temporal, as well as spatial, variations occur Pockalny et al. [1988] describe a series of evenly spaced, elongate constructional features running parallel to the ridge. Independently of the work presented here, Pockalny et al. [1988] propose a model for the origın of these features in which the rate of magmatic input to the crust oscillates with time. This is precisely what we observe in our experiments at low spreading rates, as illustrated by Figure 6: intermittent periods of melting and crustal formation, separated by periods with no melting An additional constraint on the stretching phase of seafloor spreading comes from the seismic moment budget; Solomon et al. [1988] place an upper bound of $10-20 \%$ on the proportion of seafloor spreading attributable to coseismic displacements.

The along-axis variations observed on the fast spreading East Pacific Rise are much more subdued [MacDonald et al., 1984]. It would be particularly interesting if the range of spreading rates in the Earth spanned the transition between episodic and steady state behavior, parameterized by $V_{c}$

An explanation of the along-axis variations reported by Karson et al. [1987] may lie in the instability of our solutions in three dimensions This issue invites further study.

Seismic structure. Our model predicts a distinctive structure in the uppermost mantle beneath a mid-ocean ridge. a vertical ribbon, about $60 \mathrm{~km}$ deep, where partially molten rock would probably exhibit low seismic velocity and high 
attenuation This structure would be difficult to image using the conventional reflection and refraction techniques of seismic exploration. A dense array of receivers near a mid-ocean ridge might permit imaging by seismic tomography, but no such array exists Perhaps the most promising approach would be a detailed study of surface waves with paths along and across the ridge There would still be diffıculties in imaging the ridge structure because of other lateral heterogeneities elsewhere along the path

Topography and gravity The topography of fast spreading mid-ocean ridges has traditionally been interpreted as resulting from thermal isostasy [Parsons and Sclater, 1977] Slow spreading ridges such as the Mid-Atlantic Ridge are more complicated because of the presence of an axial valley A variety of explanations have been proposed for this behavior, as discussed by Parmentier and Forsythe [1985] In addition to thermal isostasy, our model predicts two contributions to the topography dynamic topography and compositional isostasy The dynamic topography is caused by both the standard plate-driven corner flow and the flow driven by compositional buoyancy The success of the thermal isostasy model would seem to impose rather severe constraints on the magnitude of the dynamic topography and compositional isostasy It is our view, however, that since the parameters entering the thermal isostasy calculation have considerable uncertainty, topography due to the additional effects of the order of a kilometer does not necessarily violate the data We also wish to point out that even the dynamic effects of corner flow, without compositional effects may be significant

We write the mid-ocean ridge topography $h$ as a sum of four terms:

$$
h=h_{\mathrm{th}}+h_{d, \mathrm{c}}+h_{d, \mathrm{~b}}+h_{\text {comp }}
$$

associated with thermal isostasy, the dynamic effects of corner flow and buoyancy-driven flow, and compositional isostasy, respectively. The first term has been adequately discussed elsewhere and is not substantively changed as a consequence of our model

The second term is often believed to be small, especially if the viscosity beneath the ridge is much lower than in the deep mantle The following example indicates that this belief may be fallacious Suppose the viscosity takes the form $\eta(r) \sim r^{\epsilon}$, where $0<\epsilon<1$ and $r$ is the distance from the ridge axis. This might mimic the effect of nonNewtonian rheology in the high-stress region beneath the ridge. The standard corner flow problem [Batchelor, 1967, Spiegelman and McKenzie, 1987] is exactly soluble for this viscosity structure. The hydrodynamic pressure is found to be

$$
\begin{gathered}
p=-\frac{\eta(r) V_{s}}{r} \frac{\epsilon}{(1-\epsilon)} \frac{\cos (k \theta)}{\cos (k \pi / 2)} \\
k=(1-\epsilon)^{1 / 2}
\end{gathered}
$$

The surface $(\theta= \pm \pi / 2)$ has a normal stress equal to $p$ in magnitude because $\partial V_{z} / \partial z=0$; we associate this normal stress with a dynamic contribution to the topography. If $\epsilon=0$ (the usual isoviscous case), (15) gives zero, implying no contribution. We assert that this is a coincidence; any finite value of $\epsilon$ gives an infinitely deep axial valley at the ridge.
Of course, the corner flow solution is unphysical very close to the ridge axis, but this example demonstrates that it is misleading to neglect dynamic topography by appealing to the isoviscous corner flow solution For this reason, we believe that our model in its present form does not form a good basis for a detailed comparison with the observed topography, because we have not modeled the region directly beneath the ridge axis with high resolution

We now turn to the third and fourth contributions to $h$ in (14), which are particular to our model Using the simplified mathematical model described in Appendix B, it can be shown that

$$
h_{d, b}=\gamma h_{\text {comp }}
$$

where $\gamma$ depends on $r$ but is independent of viscosity and all other input parameters except, perhaps, the scaled width of the upwellıng $x$ This universality arises for the same reason that the hydrodynamic pressures and stresses associated with diapiric flow are always of order $g \Delta \rho R$ for a diapir of radius $R$ and density difference $\Delta \rho$ Our numerical results indicate that $\gamma \approx-0.5$ near the ridge axis Accordingly,

$$
h_{d, b}+h_{\text {comp }} \approx 0.5 \frac{\Delta \rho^{u-w}}{\rho} z_{\text {sol }}
$$

where $\Delta \rho^{z-w}$ is the density difference between the upwelling and the walls. Generously estımating $\Delta \rho^{w-w}=0.01 \mathrm{~g} \mathrm{~cm}^{-3}$ gives a contribution to the topography of at most a few hundred meters The effect would decay laterally over a distance of a few tens of kilometers We conclude that the consequences of our model for mid-ocean ridge topography are unlikely to be detectable in the data Our model does not offer a direct explanation for the axial valleys at slow spreading ridges.

We hesitate to embark on a treatment of the gravity field predicted by the model At short wavelengths, it seems likely that the details of the process of igneous emplacement in the crust, which we have not addressed, will probably be more important than the deeper density anomalies in the model. At long wavelengths, the gravitational effects associated with thermal isostasy will probably obscure any signal from the density anomalies beneath the ridge However, Hall et al. [1986] interpret the gravity field over slow spreading ridges as indicating a low-density root not unlike the buoyant upwelling observed in our experiments.

Structure and petrology of the oceanic crust and lithosphere By postulate, our model produces a lithosphere like that proposed by Oxburgh and Parmentier [1977], 1 e., a basaltic crust overlyıng a depleted harzburgite residue, grading into unmelted garnet-spinel lherzolite The thickness of crust produced is principally determined by the depth to the solidus of the original mantle material (see section 31 ) Hence we support the conclusions of Klein and Langmuir [1987] regarding the relationshıp between the temperature of the mantle and the thickness of crust produced

A petrological constraint that is less easily explained is that the liquids parental to MORBs are derived from well below the base of the crust While the details of the sequence of melting and fractional crystallization events remain a subject of debate [Stolper, 1980; Presnall et al., 1979], there is consensus that liquids were last in equilibrium 
with their mantle source rocks at pressures around $10 \mathrm{kbar}$ or more (depths of $30 \mathrm{~km}$ or more). This means that the percolation process used as the sole mechanism of magma migration in our model must either become so rapid that crystal-liquid equilıbrium is not maintained, or it must break down in favor of a more rapid transport process Our model does predict quite high porosities, and consequently high rates of percolation, at depths well below the surface, e.g, in Figure $5 a$. Also, the combination of high porosities and high shear stresses in the rapid upwelling may encourage the mechanism of hydraulic fracture of partial melts proposed by Nicolas [1986] Testing of this interesting but speculative inference will probably require improved understanding of the permeability and other physical properties of partial melts when subjected to shear stresses.

A second, also speculative, inference relates to the interpretation of unusual rocks found on ridges in terms of multistage melting [Duncen and Green, 1980]. Our model provides a natural mechanism whereby mantle material can experience more than one cycle of melting. Material on the periphery of the upwelling may in part originate from the adjacent walls of residual material. Thermal conduction may heat this material so that it is once again hot enough to melt, contributing liquids that are different from those produced in the first cycle of melting.

\subsection{Conclusions}

1. A self-consistent model of melting, magma migration, and buoyancy-driven circulation beneath mid-ocean ridges provides an explanation for the narrowness of the zone of crustal formation at ridges More generally, the model shows how important the changes in the intrinsic density of mantle material due to melting may be in influencing mantle flow.

2. A prediction of the model is that, at low spreading velocities, the process of crustal formation may become episodic.

3. The high porosities associated with a narrow, rapid upwelling may permit magma segregation at depths that are a large fraction of the depth to the solidus.

\section{APPENDIX A: ANALYTIC INVESTIGATION OF THE NUMERICAL RESULTS}

\section{A.1. Relationship Between $V_{s}$ and $x_{v}$}

Consider the geometry shown in Figure 7. Our objective is to estimate the width of upwelling $x_{z}$ as a function of the plate spreading rate $V_{s}$. The first constraint is the conservation of mass:

$$
V_{v} x_{v}=V_{s} z_{s o l}
$$

Here and elsewhere in the analysis, numerical factors are estimated but not calculated precisely. Equation (A1) is a statement based on the numerical experiments, in which we see that the material in the upwelling spreads out to form a layer between the solidus and the surface. We immediately introduce the variable $x$, the width of the upwelling relative to the depth of the solidus:

$$
x=\frac{x_{v}}{z_{s o l}}=\frac{V_{s}}{V_{v}}
$$

The second equality is obtained from (A1).
The upwelling is driven by the density difference $\Delta \rho^{u-w}$ between the material in the upwelling, and the adjacent residual material. Hereafter we will refer to the residual material that confines the upwelling to ether side as the "walls." In Appendix B, we justify the following approximation for the upwelling velocity

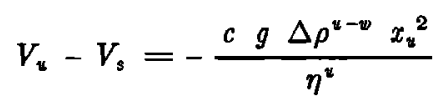

where $c \sim 01$. Note the use of $V_{u}-V_{s}$. the buoyancy drives flow relative to the plate-driven upwelling.

Density of the upwelling and walls. We now estimate the density difference $\Delta \rho^{u-v}$, by estimating the density of the upwelling and the walls at half the depth to the solidus. Adopting the notation in (6), the density of the upwelling $\rho^{*}$ is given by

$$
\rho^{u}=\rho^{m}-f_{v} \Delta \rho^{s-l}-\frac{F_{x}}{F_{0}} \Delta \rho^{m-\tau}
$$

where $f_{v}$ and $F_{v}$ are the porosity and degree of melting in the upwelling, at half the depth to the solidus. We set $F_{\text {v }}=F_{\text {tot }} / 2$, where as before, $F_{\text {tot }}$ is the total degree of melting caused by ascent from the solidus to the surface.

The porosity of the upwelling $f_{x}$ is obtained as follows. Consider the equation giving the rate of change of porosity (8) in simplified, one-dimensional form.

$$
\frac{\partial f}{\partial t}=0=-\frac{\partial u_{z}}{\partial z}-V_{\mathrm{v}} \frac{\partial f}{\partial z}+\frac{F_{\text {tot }} V_{\mathrm{u}}}{z_{\text {sol }}}
$$

The flux $u_{z}$ is obtained from Darcy's law, stated in the form $u_{z}=u_{0} f^{2}\left(u_{0}\right.$ is defined in section 2.1). Substituting into (A5), we obtain the following differential equation in $f$.

$$
\left(2 f u_{0}+V_{v}\right) \frac{\partial f}{\partial z}=\frac{F_{t o t} V_{v}}{z_{s o l}}
$$

At half the depth to the solidus, we set $f=f_{4}$ and assume $\partial f / \partial z=2 f_{v} / z_{s a l}$. This leads to a quadratic form for $f_{*}$

$$
f_{u^{2}}^{2}+\frac{V_{u}}{2 u_{0}} f_{y}=\frac{F_{t o t} V_{u}}{4 u_{0}}
$$

Since $V_{\mathrm{u}} \ll<u_{0}$ and $f_{\mathrm{u}}<<F_{\text {tot }}$, we adopt a simplified solution of (A7). The simplification amounts to neglecting the second term on the right-hand side of (A5), which represents advection:

$$
f_{v}=1 / 2\left(\frac{F_{t o t} V_{t}}{u_{0}}\right)^{1 / 2}
$$

The most significant feature of this expression is the variation of $f_{\mathrm{z}}$ with $V_{\mathrm{z}}^{1 / 2}$, arising because of the nonlinear variation of the permeability with porosity.

The density of the walls of the upwelling is given by

$$
\rho^{w}=\rho^{m}-(1-1 / 2 x) \frac{F_{t o t}}{F_{0}} \Delta \rho^{m-\tau}
$$

To understand the origin of this expression, consider the material emerging laterally from the top of the upwelling, 
where it is confined to a neck whose depth is approximately equal to the width of the upwelling $x_{z}$ (see Figure 7). This material then diverges to fill a layer between the surface and the solidus The degree of melting of the material in the middle of the neck, and therefore in the middle of the layer, is $(1-1 / 2 x) F_{t o t}$, hence we obtain (A9) Comparing (A9) with (A4), note that the density of the walls is always lower than the density of the solid in the upwelling From (A4), (A8) and (A9) we can substitute for $\Delta \rho^{u-w}=\rho^{z}-\rho^{w}$ in $(\mathrm{A} 3)$.

$$
\begin{aligned}
& V_{u}-V_{s}= \\
& \frac{c g x_{u}{ }^{2}}{2 \eta^{u}}\left[\left(\frac{F_{t o t} V_{u}}{u_{0}}\right]^{1 / 2} \Delta \rho^{s-l}-(1-x) \frac{F_{t o t}}{F_{0}} \Delta \rho^{m-\tau}\right]
\end{aligned}
$$

Note that the buoyancy of the liquid is counteracted by the negative buoyancy of the solid in the upwelling relative to the walls Finally we substitute for $V_{u}$ in terms of $x_{u}$ from (A1), to obtain the following form.

$$
(1-x) V-B x^{5 / 2} V^{1 / 2}+A x^{3}(1-x)=0
$$

where $x=x_{u} / z_{s o l}$ (as before), and $V=V_{s} / u_{0}$ The constants $A$ and $B$, both positive, are given by

$$
\begin{aligned}
A & =\beta \frac{F_{t o t}}{F_{0}} \frac{\Delta \rho^{m-\tau}}{\Delta \rho^{s-l}} \\
B & =\beta F_{t o}^{1 / 2} \\
\beta & =\frac{c}{2} \frac{z_{s o l}^{2}}{k_{0}} \frac{\eta^{l g}}{\eta^{q}}
\end{aligned}
$$

Equation (A11) is a quadratic in $V^{1 / 2}$, and can therefore be solved exactly for $V(x)$. The function is shown in Figure 8. Note that $x$ represents the width of the upwelling and $V$ represents the spreading velocity It is therefore most natural to think of $x$ as the dependent variable, although this is analytically inconvenient. The characteristics of the function $V(x)$ are described further in the text.

\section{A.2 Stability Analysis}

The analytic model presented above describes the interaction between several physical processes As a consequence, there are a number of ways we can approach analyzing the stability of the solutions obtained Here we describe two approaches that limit the regions of $V(x)$ in which stable solutions are expected

Porosity runaway. In this analysis we address the process by which the porosity in the upwelling adjusts toward its steady state value. To do so, we must distinguish between the actual value of porosity at a given time, designated $f_{z}$, and the equilibrium value $f_{e}$ The latter is defined to be the solution to (A8), 1.e., the value of $f_{e}$ is determined by the upwellng velocity $V_{v}$ The general theme of this analysis is that both $f_{\mathrm{z}}$ and $f_{\mathrm{e}}$ can fluctuate, and that these fluctuations are coupled. For example, if $f_{u}$ increases, the density of the upwelling will decrease, so we expect $V_{u}$ and $f_{e}$ to increase.

We now reexamine the equations derived above in light of the distinction between $f_{v}$ and $f_{*}$ The main modification needed is to (A5), which becomes an equation giving the rate of change of $f_{z}$ :

$$
\frac{\partial f_{\psi}}{\partial t}=-2 u_{0} f_{*} \frac{\partial f_{\psi}}{\partial z}+\frac{4 u_{0}}{z_{s o l}} f_{e}^{2}
$$

The first term on the right-hand side is the rate of compaction, expressed in terms of $f_{u}$ because it is the actual porosity that determines the flux $u_{z}$. The second term is the rate of melting, expressed in terms of $f_{e}$ using (A8). The advection term in (A5) is neglected Setting $\partial f_{*} / \partial z=2 f_{v} / z_{s o l}$, we obtain a simple form

$$
\frac{\partial f_{\mathrm{u}}}{\partial t}=\frac{1}{\tau}\left(f_{e}^{2}-f_{\mathrm{u}}{ }^{2}\right)
$$

where $\tau=4 u_{0} / z_{s o l}$

Since the density of the upwelling is determined partly by $f_{y}$, we must modify (A10) to include $f_{\text {v }}$ explicitly. In its present form, (A10) assumes that $f_{\mathrm{u}}=f_{\mathrm{e}}$. The resulting equivalent to (A11) is as follows

$$
(1-x) V-2 \beta x^{3} f_{\mathfrak{v}}+A x^{3}(1-x)=0
$$

Note that the constant $\beta$ is given in (A12c)

Consider the following perturbation from equilıbium.

$$
\begin{aligned}
f_{u} & =f_{0}\left(1+\delta_{u}\right) \\
f_{\mathrm{u}} & =f_{0}\left(1+\delta_{\mathrm{e}}\right) \\
x & =x_{0}\left(1+\delta_{\mathrm{t}}\right)
\end{aligned}
$$

This perturbation occurs at constant $V=V_{0}$ (constant spreading velocity), away from a point on $V(x)$ where $x=x_{0}$ and $f_{v}=f_{e}=f_{0}$ In order to relate $\delta_{u}$ and $\delta_{x}$, we substitute (A16a) and (A16c) into (A15) and retain the first-order terms in these small quantities:

$$
\delta_{x}=\frac{2 \beta x_{0}^{2} f_{0}}{6 \beta x_{0}^{2} f_{0}-A\left(3-4 x_{0}\right)+V} \delta_{u}
$$

From (A8), it is clear that

$$
\delta_{e}=-1 / 2 \delta_{x}
$$

Using (A17) and (A18), we can in turn relate $\delta_{e}$ to $\delta_{*}$

We now substitute the perturbed solutions (A16a) and (A16b) into the growth equation (A14).

$$
\frac{\partial f_{\mathrm{u}}}{\partial t}=\frac{2 f_{0}^{2}}{\tau}\left(\delta_{e}-\delta_{\mathrm{u}}\right)
$$

The perturbation is unstable if $\delta_{\varepsilon}>\delta_{v}$ This inequality means that the equilıbrium porosity changes more rapidly than the the actual porosity. With some manipulation of (A11), (A17) and (A18), the condition $\delta_{u}=\delta_{\varepsilon}$ leads to the following constraint on $V_{0}$ and $x_{0}$.

$-V_{0}-5 / 2 B x_{0}^{3 / 2} V_{0}^{1 / 2}+A x_{0}^{2}\left(3-4 x_{0}\right)=0$

Inspection of (A11) shows that (A20) is identical to the condition that $\partial V / \partial x=0$ For the case illustrated in Figure 7 , this transition state occurs at $V=0, x=1$ Further examination of the stability condition shows that states with higher values of $x$ are unstable.

This stability analysis demonstrates that $V(x)$ is not 
multivalued, in the sense that only one vaiue of $x$ is stable for a given spreadıng velocity. It also predicts a time scale $\tau_{v}$ for the equilibration of porosity in the upwelling.

$$
\tau_{u}=\frac{z_{\text {sol }}}{8 u_{0} f_{v}}
$$

The analysis does not, however, account for the breakdown of steady state solutions at a finite value of $V$, as was observed in the numerical experiments We therefore investigate a second instability mechanism

Oscillation of densities Detailed study of the expermment shown in Figure 6 suggests the following mechanism of instability The velocity of the upwelling is controlled by the balance between the density of the upwelling and the density of the walls If $x$ or $V_{u}$ fluctuates, the porosity in the upwelling, and hence the density, can adjust quickly However, the density of the walls does not respond until new material, melted to a different degree, is transported from the upwelling to the walls This takes a time $\tau_{v}=z_{z o l} / V_{u}$

Suppose the upwellıng becomes more rapid and $x$ decreases In response, the porosity of the upwelling increases, on the time scale $\tau_{\mathrm{z}}$ given in (A21) This increase provides positive feedback because the density of the upwelling decreases The positive feedback is controlled by the reduction in the density of the walls as $x$ decreases, as shown by (A9) However, the negative feedback is delayed because of the time needed to transport new material to the walls.

By restating this description in mathematical terms, we can demonstrate that the instability occurs below a critical value of the spreading velocity. Examining the right-hand side of (A10), we represent the delay described above through a retarded value of $x$ in the solid density term This leads to the following modified form of (A11)

$$
(1-x) V-B x^{5 / 2} V^{1 / 2}+A x^{3}\left(1-x^{\prime}\right)=0
$$

where $x^{\prime}(t)=x\left(t-\tau_{w}\right)$

Consider a trial solution that fluctuates about the steady solution $x_{0}$ obtained when the retardation effect is neglected

$$
x(t)=x_{0}\left(1+\delta \sin \omega t e^{\sigma t}\right)
$$

We expect that the most destabilizing value of $\omega$ will place the fluctuations in the density of the walls exactly out of phase with the fluctuations of density in the upwelling, i.e. $\omega \tau_{v}=\pi$ In this case, the density of the upwelling is minimum when the density of the walls is maximum, and vice versa. The retarded value of $x$ is then given by

$$
x^{\prime}(t)=x_{0}\left(1-\delta \sin \omega t e^{\sigma\left(t-r_{\psi}\right)}\right)
$$

We now substitute (A23) and (A24) into (A22) and examine the first-order terms in $\delta$ :

$$
\begin{aligned}
-V-5 / 2 B V^{1 / 2} & x_{0}^{3 / 2}+ \\
A & x_{0}^{2}\left(3+\left(e^{-\sigma \tau_{w}}-3\right) x_{0}\right)=0
\end{aligned}
$$

In this equation, $V$ is fixed and $x_{0}$ satisfies the unmodified equation (A11). Manipulating (A11) and (A25) to eliminate the terms in $V^{1 / 2}$, we obtain a more useful form:

$$
V=A x_{0}^{3}\left(\frac{1+x_{0}\left(2 e^{-\sigma \tau_{w}}-1\right)}{5-3 x_{0}}\right)
$$

Consider first the transitional case where $\sigma=0$ The simultaneous solution of (A26) and (A11) defines a critical point on $V(x)$, designated by $V=V_{c}$. This intersection is shown graphically in Figure 8 At this point, a stable state can persist in which $V$ is constant and $x$ oscillates infinitesimally about $x_{0}$

We now consider the case when $\sigma>0$, to identify states that become unstable as the oscillation grows with time. The new simultaneous solution to (A26) and (A11) must still lie on the curve $V(x)$ defined by (A11). Inspection of (A26) shows that increasing $\sigma$ will move the point of intersection to a lower value of $V, 1 \mathrm{e}, V<V_{b}$. The reverse applies when $\sigma<0,1 \mathbf{e}$, when $V>V_{c}$, the oscillatory state decays with time

The spreading velocity corresponding to $V_{c}$ represents a point of transition At higher velocities, fluctuations in $x$ are damped, and a steady state should persist. At lower velocities, fluctuations grow, and a steady state cannot be reached This analysis also identifies the tıme scale $\tau_{w}$ in which the density of the walls equilibrates

\section{APPENDIX B· SiMPLE MOdEL FOR BUOYANCY-DRIVEN FLOW}

In two-dimensional incompressible flow, the stream function $\psi$ satisfies a biharmonlc equation with a source term,

$$
\nabla^{4} \psi=-\frac{g}{\eta} \frac{\partial \rho}{\partial x}
$$

where $g$ is the acceleration due to gravity, $\eta$ is the viscosity (assumed constant), $\rho$ is the fluid density, and $x$ is the horizontal coordinate. As usual, the horizontal and vertical components of velocity are $\partial \psi / \partial z$ and $-\partial \psi / \partial x$, respectively The vertical coordinate $z$ is positive upward, with $z=0$ at the surface.

In our problem of a mid-ocean ridge with differentiation beneath the ridge, the source term on the right-hand side is related to $\psi$ through advection. However, we can understand many properties of the system by treating the righthand side as known. It is then easy to decompose the solution,

$$
\psi=\psi_{c}+\psi_{b}
$$

where $\psi_{c}$ is the usual corner flow stream function and $\psi_{b}$ is associated with the buoyancy-driven flow. The former is obtained by solving $\nabla^{4} \psi_{c}=0$ with the usual kinematic boundary conditions at $z=0$ associated with moving plates [Batchelor, 1967; Spiegelman and McKenzie, 1987]. The latter is a particular solution to (B1) with a zero velocity boundary condition at $z=0$ Equation (B2) shows the linear superposition of these two components, combining the effects of plate motion and buoyancy.

For mathematical simplicity, we choose to approximate the buoyancy in the upwelling by a separable function in which the $z$ dependence is exponential,

$$
\frac{\partial \rho}{\partial x}=-\Delta \rho e^{q z} \frac{\partial \phi}{\partial x}
$$

where $\phi(x)$ is a positive function with $\phi(0)=1$, and buoy- 
ant material has $\Delta \rho>0$. It is then straightforward to obtain the following form for $\psi_{b}$ satisfying $\partial \psi / \partial x=\partial \psi / \partial z=0$ at $z=0$.

$$
\begin{gathered}
\psi_{b}=\frac{g \Delta \rho}{\eta}\left[\frac{2}{\pi}\right]^{1 / 2} \\
\int_{0}^{\infty} \frac{g(k)}{\left(q^{2}-k^{2}\right)^{2}}\left[e^{k z}-(q-k) z e^{k z}+e^{q z}\right] \sin k x d k \\
g(k)=\left[\frac{2}{\pi}\right]^{1 / 2} \int_{0}^{\infty} \frac{\partial \phi}{\partial x} \sin k x d k
\end{gathered}
$$

We further choose $\phi(x)=\exp \left(-x^{2} / x_{0}^{2}\right)$ because it is the simplest function with the right physical and symmetry properties and a simple Fourier transform. By comparison with the detailed models in the text, we can identify $q^{-1}$ with the depth to the solidus $z_{s o l}$, and $x_{0}$ with the width of the upwelling $x_{v}$

Equation (B4) is easily evaluated for a range of choices of $x_{u} / z_{s o l}$, the only free parameter in the nondimensionalized solution As expected, the flow is similar to that in the interior of a diapir (although the top boundary condition is different). The upwelling velocity $V_{z}$ at depth $z_{\text {sol }}$ beneath the ridge at $x=0$ can be approximated by

$$
V_{\mathrm{z}}-V_{s} \approx \frac{005 g \Delta \rho x_{u}^{1.6} z_{s o j}^{0.4}}{\eta}
$$

in the range $0.2<x_{v} / z_{\text {sol }}<1$. In section 4 of the text we adopt an approximation to (B6) that is reasonably good for the range of $x_{w} / z_{s o l}$ of interest:

$$
V_{\mathrm{v}}-V_{\mathrm{s}}=\frac{0.1 g \Delta \rho x_{\mathrm{u}}^{2}}{\eta}
$$

Acknowledgments. We have benefited from discussions with Ed Stolper, Brad Hager, and other colleagues at Caltech. The manuscript was improved after comments by J. Brodholt and an anonymous reviewer. This work was supported in part by NSF grant EAR8618511. Contribution No. 4555, Division of Geological and Planetary Sciences, California Institute of Technology, Pasadena.

\section{REFERENCES}

Batchelor, G. K., An introduction to fluid dynamics, Cambridge University Press, 1967.

Bottinga, Y., and L. Steinmetz, A geophysical, geochemical, petrological model of the submarine lithosphere, Tectonophysics, 55, 311-347, 1979.

Cooper, R. F., and D. L. Kohlstedt, Solution-precipitation enhanced diffusional creep of partially molten olivine-basalt aggregates during hot-pressing, Tectonophysics, 107, 207-233, 1984.

Cooper, R. F., and D. L. Kohlstedt, Rheology and structure of olivine-basalt partial melts, J. Geophys. Res., 91, 9315-9323, 1986.

Craig, C. H., and D. McKenzie, The existence of a thin lowviscosity layer beneath the lithosphere, Earth Planet. Sci. Lett., $78,420-426,1986$.

Detrick, R. S., P. Buhi, E. Vera, J. Mutter, J. Orcutt, J. Madsen, and T. Brocher, Multichannel seismic imaging of a crustal magma chamber along the East Pacific Rise between $9^{\circ} \mathrm{N}$ and $13^{\circ} \mathrm{N}$ Nature, 326, 35-41, 1987.

Duncan, R. A., and D. H. Green, Role of multistage melting in the formation of oceanic crust, Geology, 8, 22-26, 1980.

Hager, B. H., and R. W. Clayton, Constraints on the structure of mantle convection using seismic observations, flow models and the geoid, in Mantle Convection, edited by W. R. Peltier, Gordon and Breach, New York, in press, 1988.

Hall, S. A, J. F. Casey, and D. L. Elthon, A possible explanaiion of gravity anomalies over mid-ocean ridges, J. Geophys. Res., 91, $3724-3738,1986$.

Houseman, G. A., The deep structure of ocean ridges in a convecting mantle, Earlh Planet. Sci. Lett., 64, 283-294, 1983.

Karson, J. A., G. Thompson, S. E. Humphries, J. M. Edmond, W. B. Bryan, J. R. Brown, A. T. Winters, R. A. Pockalny, J. F. Casey, A. C. Campbell, G. Klinkhammer, M. R. Palmer, R. J. Kinzler, and M. M. Sulanowska, Along-axis variations in seafloor spreading in the MARK area, Noture, 328, 681-685, 1987.

Klein, E. M., and C. H. Langmuir, Global correlations of ocean ridge basalt chemistry with axial depth and crustal thickness, $J$. Geophys. Res., 92, 8089-8115, 1987.

Kushiro, I., Viscosity of partial melts in the upper mantle, J. Geophys. Res., g1, 9343-9350, 1986.

Lewis, B. T. R., The East Pacific Rise and the thermal model, $J$. Geophys. Res., 88, 3348-3354, 1983.

Maaloe, S., and A. Scheie, The permeability-controlled accumulation of primary magma, Contrib. Mineral. Petrol., 81, 350-357, 1982.

McClain, J. S., and C. A. Atallah, Thickening of the oceanic crust with age, Geology, 14, 574-576, 1986.

McClain, J. S., J. A. Orcutt, and M. Burnett, The East Pacific Rise in cross-section: A seismic model, J. Geophys. Res., 90, $8627-8640,1985$.

MacDonald, K. C., J. C. Sempere, and P. J. Fox, East Pacific Rise from Sequeiros to Orozeo Fracture Zones: Along-strike continuity of axial neovolcanic zone and structure and evolution of overlapping spreading centers, J. Geophys. Re8., 89, 6049-6069, 1984.

McKenzie, D. P., The generation and compaction of partial melts, J. Petrol., 25, 713-765, 1984.

McKenzie, D. P., ${ }^{230} \mathrm{Th}-2{ }^{238} \mathrm{U}$ disequilibrium and the melting process beneath ridge axes, Earth Planet. Sci. Lett., 72, 149-157, 1985 a.

McKenzie, D. P., The extraction of magma from the crust and mantle, Earth Planet. Sci. Lett., 74, 81-91, 1985b.

Phipps Morgan, J., Melt migration beneath mid-ocean spreading centers, Geophys. Res. Letl., 14, 1238-1241, 1987.

Nicolas, A., A melt extraction model based on structural studies in mantle peridotites, J. Petrol., 27, 999-1022, 1986.

Nicolas, A., and M. Jackson, High temperature dikes in peridotites: Origin by hydraulic fracturing, $J$. Petrol., 23, 568-582, 1982.

Oxburgh, E. R., and E. M. Parmentier, Compositional and density stratification in oceanic lithosphere - Causes and consequences, J. Geol. Soc. London, 199, 343-355, 1977.

Parmentier, E. M., and D. W. Forsythe, Three-dimensional flow beneath a slow-spreading ridge axis: A dynamic contribution to the deepening of the median valley toward fracture zones, $J$. Geophys. Res., g0, 678-684, 1985.

Parsons, B., and J. G. Sclater, An analysis of the variation of ocean floor bathy metry with age, J. Geophys. Res., 82, 803-827, 1977.

Pockalny, R. A., R. S. Detrick, and P. J. Fox, Morphology and tectonics of the Kane transform from Sea Beam bathymetry data, $J$. Geophys. Res., 99, 3179-3193, 1988.

Presnall, D. C., J. R. Dixon, T. H. O'Donnell, and S. A. Dixon, Generation of mid-ocean ridge tholeiites, J. Petrol., 20, 3-35, 1979.

Rabinowicz, M., A. Nicolas, and J. L. Vigneresse, A rolling mill effect in the asthenosphere beneath oceanic spreading centers, Earth Planet. Sci. Lett., 67, 97-108, 1984.

Rabinowicz, M., C. Ceuleneer, and A. Nicolas, Melt segregation and flow in mantle diapirs below spreading centers: Evidence from the Oman ophiolite, J. Geophys. Res., 92, 3475-3486, 1987.

Ribe, N., The generation and compaction of partial melts in the Earth's mantle, Earth Planet. Sci. Lett., 73, 361-376, 1985.

Rigden, S. M., T. J. Ahrens, and E. M. Stolper, Densities of silicate liquids at high pressures, Science, 226, 1071-1074, 1984.

Scott, D. R., The competition between percolation and circulation in a deformable porous medium, J. Geophys. Res., 93, 6451-6462, 1988.

Scott, D. R., and D. J. Stevenson, Magma ascent by porous flow, J. Geophys. Res., 91, 9283-9296, 1986.

Sleep, N. H., Segregation of magma from a mostly crystalline mush, Geol. Soc. Am. Bull., 85, 1225-1232, 1974. 
Solomon, S. C., P. Y. Huang, and L. Meinke, The seismic moment budget of slowly spreading ridges, Nature, \$94, 58-69, 1988.

Spiegelman, M., and D. P. McKenzie, Simple 2-D models for melt extraction at mid-ocean ridges and island arcs, Earth Planet. Sci. Lett., 89, 137-152, 1987.

Stolper, E. M., A phase diagram for mid-ocean ridge basalts: Preliminary results and implications for petrogenesis, Contrib. Mineral. Petrol., 74, 13-27, 1980.

Turcotte, D. L., and J. L. Ahern, A porous flow model for magma migration in the asthenosphere, J. Geophys. Res., 88, 767-772, 1978.

Turcotte, D. L., and E. R. Oxburgh, Finite amplitude convection cells and continental drift, J. Fluid Mech., 28, 29-42, 1967.

Vaughan, P. J., D. J. Kohlstedt, and H. S. Waff, Distribution of the glass phase in hot-pressed, olivine-basalt aggregates: An electron microscopy study, Contrib. Mineral. Petrol., 81, 253-261, 1982.
Vine, F. J., Spreading of the ocean floor: New evidence, Science, 154, 1405-1415, 1966.

Wood, B. J., and D. A. Yuen, The role of lithospheric phase transitions on seafloor flattening at old ages, Earth Planet. Sci. Lett., $66,303-314,1983$

D. R. Scott, Seismological Laboratory, Department of Geological and Planetary Sciences, California Institute of Technology, Pasadena, CA 91125.

D. J. Stevenson, Department of Geological and Planetary Sciences, California Institute of Technology, Pasadena, CA 91125.

(Received November 10, 1988; revised August 2, 1988;

accepted September 26, 1988.) 